\title{
Quando a aula termina: a política econômica das manifestações dos sindicatos de professores na Quarta República de Gana ${ }^{1}$
}

\author{
When the chalks are down: the political economy of teachers' unions protest \\ actions under Ghana's Fourth Republic \\ Cuando la clase termina: la política económica de las manifestaciones de los \\ sindicatos de profesores en la Cuarta República de Gana
}

AKWASI KWARTENG AMOAKO-GYAMPAH

\begin{abstract}
Resumo: O presente artigo examina os protestos dos sindicatos de professores sob a Quarta República de Gana. Situando a análise dentro da evolução de sua economia política, eu mostro como as restrições na política econômica de Gana, bem como sua macroeconomia muitas vezes instável, influenciaram e moldaram os atos de protestos, assim como condicionou as respostas dos governos às demandas dos sindicatos dos professores.
\end{abstract}

Palavras-chave: manifestações de professores; economia; Quarta República de Gana.

\begin{abstract}
This article examines teachers' unions protest actions under Ghana's Fourth Republic. Situating the analysis within Ghana's evolving political economy, I show how constraints in Ghana's political economy as well as its often-faltering macro-economy have influenced and shaped teachers protest actions as well as conditioned governments' responses to teachers' unions' demands.
\end{abstract}

Keywords: teachers' protest actions; economy; Ghana's Fourth Republic.

Resumen: El presente artículo examina las protestas de los sindicatos de profesores bajo la Cuarta República de Ghana. Situando el análisis dentro de la evolución de su economía política, muestra cómo las restricciones en la política económica de Gana, así como su macroeconomía muchas veces inestable, influenciaron y moldearon los actos de protestas, así como condicionaron las respuestas de los gobiernos a las demandas de los sindicatos de los profesores.

Palabras clave: manifestaciones de profesores; economía; Cuarta República de Gana. 


\section{INTRODUÇÃO}

A docência tem sido uma profissão importante e continua a desempenhar um papel crucial em todas as partes do mundo. Tem sido um caminho fundamental para a mobilidade social e o emprego da classe trabalhadora e, às vezes, da população de classe média (Robertson, 2000). Muitas vezes, o ensino teve lugar dentro de um contexto político e econômico onde a educação era considerada um bem público e de responsabilidade do Estado até recentemente, quando, sob a influência das ortodoxias neoliberais, a maioria dos governos reduziu consideravelmente seus orçamentos educacionais (Compton \& Weiner 2008). No entanto, a maioria dos estados se esforça para manter um controle firme sobre o setor de educação devido ao seu potencial como uma ferramenta para o controle social e o desenvolvimento nacional. Os professores, sendo os principais interessados na educação, também procuram promover o seu interesse e facilitar a sua mobilidade social através do sistema educacional. A contribuição dos professores para a formação de pessoal qualificado necessário para o desenvolvimento nacional é reconhecida mundialmente. No entanto, a maioria dos países, particularmente os do Hemisfério Sul, relutam em resolver a multiplicidade de desafios enfrentados pelos professores e pela profissão docente (ver Sang, 2002). Os professores têm, portanto, procurado trabalhar com seus sindicatos para controlar os efeitos das regulamentações estatais que limitam seus salários, sua segurança no emprego e que moldam suas condições das maneiras que considerem apropriadas. O movimento sindical de professores tornou-se uma ferramenta para os professores se afirmarem no setor educacional.

Como em outros lugares do mundo, os professores de Gana são fundamentais não apenas para o aparato educacional, mas também para o mecanismo político. Seu papel como profissionais que orientam normas e valores sociais na futura geração de jovens líderes torna-os indispensáveis para o Estado. O estado de Gana considera seus professores como agentes de controle social e desenvolvimento nacional. Contudo, nos últimos tempos, os desenvolvimentos no campo do ensino apontam para o fato de que, embora o estado ganense espera que seus professores trabalhem assiduamente como seus agentes, dificilmente os recompensa adequadamente em termos de remuneração (ver Osei 2006; AmoakoGyampah 2015). Embora a remuneração dos professores tenha melhorado significativamente desde a década de 2000, a maioria dos professores continua se queixando da incoerência de seus ganhos mensais (Amoako-Gyampah, 2015). Além da má remuneração, alguns professores de Gana trabalham sob condições estressantes. Eles dão aulas em salas superlotadas, dão aulas para crianças debaixo de árvores e trabalham em comunidades que não têm acesso a serviços sociais 
básicos. Mesmo sob essas condições difíceis, espera-se que os professores de Gana garantam uma taxa de aprovação de cem por cento. Eles são frequentemente acusados por indivíduos, pais, comunidades e pelo governo de fracassar no sistema educacional. No entanto, do ponto de vista dos professores, os governos ao longo dos anos não fizeram o suficiente para melhorar suas condições de serviço.

Subsequentemente, o prestígio concedido aos professores no passado está diminuindo rapidamente, na medida em que os professores são classificados pelo "olhar público" como estando entre os profissionais menos bem pagos do país. Professores em Gana se organizaram através de seus sindicatos para protestar contra a deterioração das condições trabalhistas e para exigir uma remuneração justa e melhores condições de trabalho. O estado, no entanto, raramente concorda com essas demandas. Consequentemente, as greves e as ações de protesto parecem ter se tornado um ritual anual no setor de educação desde 1992. Este artigo é uma tentativa do historiador de contextualizar as ações de protesto dos professores organizados, fundamentando a análise na economia política de Gana. Não pretendo dar uma descrição detalhada desses atos de protesto; em vez disso, enfatizo de que maneiras esses protestos se manifestaram, que fatores moldaram e condicionaram essas ações e como os que estão no poder responderam. Limitarei a minha análise ao período das administrações do Congresso Nacional Democrático (NDC) e do Novo Partido Patriótico (NPP) entre 1992/3 e 2008. Isto permite um exame dos atos de protesto dos professores sob os dois diferentes governos (Congresso Nacional Democrata, de 1992/93 - 2000 e o Novo Partido Patriótico, de 2001 a 2008) que reinaram desde a inauguração da Quarta República, nos sensibilizando para condições semelhantes e diferentes sob os dois governos nos quais precipitaram os protestos dos professores, bem como a similaridade ou não das respostas desses governos aos protestos docentes. $\mathrm{O}$ artigo estrutura-se em seis seções. A introdução é seguida pelo contexto e origem do movimento sindical de professores em Gana. A próxima seção fornece um apanhado do trabalho e da economia política em desenvolvimento no Gana. A seção traz uma descrição dos atos de protesto dos professores sob o regime NDC, e a seção cinco traz um relato dos atos de protesto sob a administração da NPP. A seção seis é uma conclusão que liga as linhas de argumentos de todas as seções.

\section{CONTEXTO E ORIGEM DO MOVIMENTO SINDICAL DE PROFESSORES EM GANA}

Alguns relatos do desenvolvimento do sindicalismo de professores em Gana são necessários como preliminares. Atualmente, existem dois grandes sindicatos de professores representando os docentes no nível pré-terciário em 
Gana $^{2}$. Estes são: a Associação Nacional de Professores do Gana (GNAT) e a Associação Nacional dos Professores Licenciados (NAGRAT). A GNAT é o mais antigo e o maior entre os sindicatos de professores. Os professores estão entre os primeiros grupos de trabalhadores a formar associações em Gana. De fato, a formação de sindicatos de professores pode ser rastreada até a década de 1920. A associação de professores mais antiga foi formada entre os docentes das escolas públicas por volta de 1926 e chamava-se Associação de Professores das Escolas Públicas (GSTA) (ver Amoako 2014a; 2014b; 2014c; Darkwah 2014). Acredita-se que a formação desta associação foi patrocinada pelo então diretor colonial de Educação, J. D. Oman (Amoako 2014a). O objetivo da GSTA era ser não-sectária e não-política e concentrar-se em melhorar o ensino em sala de aula e as questões relacionadas à profissão (Darkwah 2014, 6). A exigência de salários e de condições de serviço melhores não poderia ter surgido porque, seu patrocinador, o diretor de educação - sendo um representante do governo - não poderia ter professores organizados para fazer exigências ao governo por melhores condições de serviço e aumento de salários para professores. A GSTA permaneceu adormecida durante toda a década de 1930 e foi revivida e rebatizada como a União Nacional dos Professores (NUT) na década de 1940. Como Darkwah (2014) sugeriu, do ponto de vista do ativismo moderno, essa primeira associação de professores não deve ter sido um bom pedigree para os sindicatos de professores subsequentes.

A primeira associação de professores em Gana, organizada em princípios sindicais, surgiu no início da década de 1930. Foi nomeado o Sindicato dos Professores das Escolas Assistidas (ASTU) porque representava o interesse de professores que trabalhavam em escolas assistidas - isto é, escolas administradas por missões cristãs com assistência em forma de subvenções do governo colonial (ver Amoako 2014; 2014b; 2014c). O ASTU foi formado em 1932 e foi oficialmente inaugurada em 1933 (ver Amoako 2014a). Sua formação foi motivada por um corte nos gastos do governo com educação. O corte afetou mais os professores da escola missionária, já que a doação concedida a suas missões foi reduzida em $25 \%$. Subsequentemente, a maioria dos professores das escolas missionárias foram demitidos e aqueles que foram retidos tiveram seus salários reduzidos consideravelmente (ver Amoako 2014a; Darkwah 2014). O ASTU surgiu para protestar e reverter os efeitos adversos do corte orçamentário do governo em professores de escolas missionárias. Eles adotaram o que pode ser descrito como estratégias sindicais, como protestos, petições, delegações e grupos de influência dos membros africanos da Assembleia Legislativa, para lutar contra 
as reduções (Darkwah 2014; Amoako 2014a). Eventualmente, o ASTU conseguiu persuadir o governo a retirar o corte proposto (Amoako 2012, p. 50). Em 1937, o ASTU foi renomeado para União dos Professores da Costa Dourada (GCTU) essa mudança de nome foi necessária para evitar seu caráter sectário e para abrir suas portas para professores de todos os níveis.

Na década de 1950, várias organizações de professores foram formadas, além do GCTU e da NUT. A maioria dessas associações foi formada com base nas afiliações de denominação de igrejas, áreas temáticas, níveis de qualificação educacional e nível do sistema educacional no qual os professores lecionavam (Amoako 2014a; 2014b; 2014c). Por exemplo, haviam os sindicatos de professores das escolas Católica, Metodista e Presbiteriana; a African Graduate Teachers Association (Associação Africana dos Professores Licenciados); a Mathematics Teachers Association (Associação dos Professores de Matemática); e a Training College Teachers' Association (Associação da Faculdade de Formação de Professores) (AsieduAkrofi 1971, p. 25; Amoako 2014a). As tentativas de unificar esses sindicatos em uma única organização de professores foram frustradas pelo mal-entendido entre a NUT e o GCTU. Sua divergência girou em torno da questão da estratégia organizacional e da luta pelas posições de liderança. O GCTU favoreceu uma associação de professores que operava como sindicato profissional, enquanto a NUT defendia uma organização de professores que operasse sobre princípios sindicais (Amoako 2014a; 2014b; 2014c). Além do desacordo quanto a estratégia organizacional, tanto o GCTU quanto a NUT afirmavam representar mais os professores no país e por isso mereciam assumir o papel de liderança se eles se unissem em um único sindicato ${ }^{3}$. Foi necessária a intervenção do governo e a promulgação do Industrial Relations Act, 1958, para obrigar todas as organizações de professores a se unirem a outros trabalhadores do setor educacional para formar um único sindicato, que foi denominado de União de Professores e Trabalhadores de Instituições de Ensino (UTEIW). Esta união foi inaugurada em dezembro de 1958 e foi afiliada à organização sindical, o Ghana Trade Union Congress (GTUC) (Amoako 2014a, pp. 68-69). Em 1960, a UTEIW mudou seu nome para União dos Professores e Serviços Culturais (UTCS) e, em 1962, rompeu com o GTUC, formando a Ghana National Association of Teachers (Associação Nacional de Professores de Gana) ${ }^{4}$.

A GNAT permaneceu como o único sindicato para professores de nível básico até o surgimento de um novo sindicato - a Associação Nacional de Professores Licenciados (NAGRAT), no início dos anos 90. A NAGRAT começou 
como um grupo de pressão dentro da GNAT até 1998, quando finalmente se rompeu e se tornou o segundo sindicato dos professores no setor da educação, representando principalmente o interesse dos professores licenciados no serviço educativo do Gana (Amoako 2014b; Amoako-Gyampah 2015). As razões para a formação da NAGRAT são variadas e contestadas (ver Darkwah 2014). No entanto, a preocupação central que desencadeou a formação do sindicato parecia ter sido a percepção de que a liderança da GNAT era indiferente às preocupações de seus membros licenciados (Amoako, 2014c). Por exemplo, os professores diplomados não conseguiam entender por que a GNAT estava relutante em liderar as demandas destes professores para que fossem colocados em uma escala salarial separada, recomendada pela Gyampo Salary Revision Commission (Comissão de Revisão Salarial Gyampo) ${ }^{5}$ (ver Darkwah 2014). Quaisquer que sejam as razões que levaram os professores licenciados a se separarem da GNAT; a NAGRAT tornou-se uma das principais mediadoras no campo de trabalho da educação. Tendo fornecido este breve relato do sindicalismo de professores em Gana, é imperativo que analisemos o trabalho e a economia política em evolução de Gana. Isso fornecerá um contexto amplo para a discussão subsequente das queixas e protestos dos professores. A próxima seção, portanto, fornece um apanhado do trabalho e da economia política de Gana a partir dos anos 1950.

\section{TRABALHO E ECONOMIA POLÍTICA DE GANA EM EVOLUÇÃO}

Desde a sua independência em 1957, Gana testemunhou nove mudanças no governo, incluindo quatro golpes militares. O último golpe levou ao poder Jerry John Rawlings, que permaneceu no cargo como ditador militar até 7 de janeiro de 1993, quando a quarta república foi inaugurada, e continuou como presidente eleito constitucionalmente até 2000, quando seu partido, o Congresso Nacional Democrático (NDC) perdeu o poder para a oposição Novo Partido Patriótico (NPP), liderada por John Agyekum Kufour. Para a maior parte da história política pós-colonial de Gana, tomando emprestadas as palavras de Jeon (1998), “a má gestão econômica tem sido a fonte mais comum de insatisfação. Problemas com a distribuição de recursos entre os grupos de interesse, juntamente com a estagnação econômica, frequentemente criavam condições para o protesto político" (p.

$5 \quad$ N.A.: O governo de Gana, tendo identificado problemas na a estrutura salarial do setor público, constituiu a Gyampo Salary Review Commission (Comissão de Revisão Salarial de Gyampo) para estudar a estrutura de enquadramento e salário do setor. A comissão recomendou que os professores licenciados e não licenciados deveriam ser colocados em uma estrutura hierárquica separada para fins salariais (Daily Graphic Report of the Gyampo Salary Review Commission, 11 de maio de 1994, p. 6.) 
218). O trabalho organizado tem, na maioria dos casos, sido muito ativo em tais protestos políticos. Adu-Amankwah e Tutu (1997, p. 207) observaram que as políticas econômicas do governo, que abrangem o período após a independência, tiveram implicações diferentes para o trabalho e contribuíram para moldar as relações de trabalho, bem como as relações entre governo e sindicato.

De fato, o descontentamento político após o fraco desempenho econômico do governo Nkrumah ${ }^{6}$ levou ao primeiro golpe no país em 1966. Embora o movimento sindical estivesse intimamente ligado ao governo do CPP, muitas vezes haviam greves de trabalhadores em resposta ao desempenho econômico sombrio do governo do CPP, alguns dos quais tomaram perspectivas nacionais, envolvendo a maioria dos trabalhadores do setor público (ver Jefferies, 1978; Kraus, 1979). Não há dúvida de que a agitação dos trabalhadores aumentou a impopularidade do governo de Nkrumah e sua eventual queda. Da mesma forma, a oposição popular à desvalorização em meio ao declínio econômico liderado pelos trabalhadores desencadeou, em partes, o golpe que derrubou o governo de Busia em 1972 (Kraus 2008; Jefferies 1982). O Conselho Nacional de Redenção (NRC) e o Conselho Militar Supremo (SMC I e II), o regime que foi estabelecido após a derrubada de Busia, foi expulso do poder por causa do fraco desempenho econômico e altos níveis de corrupção oficial. O golpe que levou Rawlings ao poder ocorreu logo depois do caos político que foi provocado em parte por greves agitadas de trabalhadores, após o fracasso do governo do Partido Popular Nacional (PNP), liderado por Limann, de deter o declínio econômico de Gana (ver Jeon 1998, p. 220).

O desempenho econômico alarmante e o crescimento instável de Gana desde a sua independência, junto com o declínio econômico persistente na década de 1970 e a incapacidade do regime liderado por Rawlings de resolver os problemas econômicos de Gana através de uma política nacional, levou à adoção do Fundo Monetário Internacional (FMI) e das políticas de ajuste estrutural adaptadas do Banco Mundial no início dos anos 80. Com a implementação das políticas de ajuste, embora austeras, Gana começou a experimentar um crescimento econômico moderado e constante após 1985, experimentando taxas de crescimento mais altas nos anos 2000 (Lindsay 2011; Aryeetey \& Kanbur 2008). Apesar desse crescimento modesto, o país não conseguiu progredir muito. O Gana continuou a depender de suas commodities de exportação tradicionais ouro e cacau (ver Aryeetey \& Kanbur 2008; Bob-Milliar \& Bob-Milliar, 2010). De fato, no início da década de 1990, o cacau contribuiu com $50 \%$ a $60 \%$ da receita de exportação, cerca de $20 \%$ da receita do governo e cerca de $7 \%$ do PIB. Essa 
tendência continuaria na década de 2000, já que o crescimento durante a primeira metade dos anos 2000 foi impulsionado principalmente pelo desempenho das exportações de ouro e cacau - na verdade, o Gana se beneficiou da guerra civil na Costa do Marfim e do consequente aumento do preço mundial do cacau (Lindsay 2011a, p. 7; Lindsay 2011b, p. 13). Mais uma vez, o enorme influxo de ajuda externa como principal fonte de investimento durante o período de ajuste tornou os esforços de crescimento de Gana insustentáveis, uma vez que a redução da entrada de ajuda externa na década de 1990 prejudicou a economia do país (Killick 2000).

A macroeconomia de Gana nos anos 90 foi marcada pela instabilidade. Em grande parte, isso se deveu aos gastos excessivos do governo e às flutuações nos preços internacionais das commodities. O problema piorou quando o FMI suspendeu os fluxos de crédito concessional sob seu contrato de empréstimo com o país como punição pela perda de disciplina fiscal do governo NDC (Lindsay 2011b). Além de ter que pagar dívidas provenientes de empresas estatais mal administradas, o governo conseguiu, com dificuldade, gerar receita antecipada devido a reviravoltas políticas. Além disso, o governo empenhou-se nas despesas "politicamente motivadas" no segundo turno das eleições de 1992 e 1996, fornecendo orçamento para infraestrutura rural e aumentando os salários do setor público para ganhar votos rurais e urbanos, respectivamente (Lindsay 2011b, p. 16). Depois das eleições de 1992 , no entanto, o governo do NDC estava disposto a tomar medidas duras para consertar os desequilíbrios fiscais que resultaram de seus gastos imprudentes politicamente motivados. Haynes (1995) observou que “após as eleições, o governo queria mostrar ao Banco Mundial que sua capitulação aos funcionários públicos era apenas uma tática para ajudá-lo a obter sucesso eleitoral" (p. 113). Posteriormente, o último orçamento do PNDC anunciado em 5 de janeiro de 1993, dois dias antes da inauguração da Quarta República, era nada menos do que austero. Um aumento de sessenta por cento no preço da gasolina afetou todos os setores da economia, elevando astronomicamente os preços de bens e serviços - em alguns casos, até 100\% (Jeon 1998, p. 223; Haynes 1995). Operando dentro das restrições das condições do FMI e do Banco Mundial, o governo do NDC foi forçado a reduzir drasticamente os gastos públicos depois de 1993. Para piorar a situação, a inflação subiu precipitadamente e o cídi do $\mathrm{Gana}^{7}$ seguiu desvalorizando muito (Haynes 1995, p. 110). De fato, em dezembro de 1995, a inflação estava em 70,8\% (Jeon 1998, p.223). Por volta desse mesmo período, o cídi havia sofrido uma redução de cerca de 218 vezes em seu valor, em

N.T.: Unidade monetária do Gana. 
relação ao dólar americano desde 1983 (Haynes 1995, 110). Com o impacto de uma economia tão ameaçadora no trabalho, era menos provável que as organizações de trabalhadores agissem com moderação.

Segundo Haynes (1995), "o primeiro ano da Quarta República" foi marcado pelas agitações e greves trabalhistas devido ao impacto inflacionário seguido do aumento do preço da gasolina, e aos "níveis salariais inadequados dos trabalhadores de Gana em geral" (p. 110). De fato, pode-se dizer que os trabalhadores estivesses provavelmente reagindo à negligência de longa data e ao empobrecimento contínuo, desde a implementação das políticas de ajuste estrutural nos anos 80. A capacidade do governo do PNDC de usar medidas repressivas para combater os protestos sociais havia assegurado que os trabalhadores concordassem com suas medidas econômicas austeras e seu impacto sobre seus salários e condições de vida após a implementação das políticas de ajuste nos anos 80 (ver Herbst 1993; Gyimah-Boadi). \& Essuman-Johnson 1993). Certamente, entre 1986 e 1990, o salário mínimo havia perdido cerca de 20\% de seu valor; houve uma queda adicional de 13\% entre 1991 e 1993 (Haynes 1995, p. 111) e até o final de 1994, os salários mensais dos trabalhadores do setor público tinham diminuído $22 \%$ - o maior corte nos primeiros quatro anos após transição (Hutchful 2002, pp. 90-91; Amoako 2014c, p. 19).

Para solucionar os desafios econômicos, o governo NPP adotou com relutância, dentre outras medidas, a iniciativa Países Pobres Altamente Endividados (HIPC) em 2001. A recuperação alcançada permitiu ao governo estabilizar a macroeconomia, criar um ambiente favorável aos negócios (ver Bob-Milliar \& Bob-Milliar 2010; Killick 2010; Amoako-Gyampah 2015) e introduziram algumas medidas significativas de intervenção social. Entre 2002 e 2005, a disciplina fiscal do governo - "maior controle sobre os gastos, com limites rígidos de caixa para os ministérios de gastos" (Killick 2010, p. 415) - ajudou a reduzir o déficit orçamentário de Gana e a taxa de expansão monetária. Killick (2010, p. 415) estima que o crescimento monetário foi reduzido de 50\% em 2002 para $14 \%$ em 2005, e que a taxa de inflação caiu para um único dígito nos primeiros meses de 2006. Da mesma forma, a depreciação crescente do cídi parou por um tempo. Outros setores da economia demonstraram fortemente que o Banco Mundial comentou que Gana estava "no meio da aceleração do crescimento econômico" (citado em Killick, 2010, p. 415).

Deve-se observar, no entanto, que, apesar das fortes perspectivas de crescimento econômico, o governo do NPP não alcançou suas metas econômicas. Lindsay (2011b) observou que devido ao planejamento econômico equivocado do governo NPP após 2004, em janeiro de 2009, o país mergulhou em crises financeiras - o déficit orçamentário atingiu 14,5\% do PIB, a desvalorização da 
moeda ressurgiu e as tendências inflacionárias voltaram. De fato, enquanto a inflação permaneceu moderada até 2007, em 2008, ela quase dobrou para $20 \%$ (Killick 2010, p. 417). Lindsay (2011b) observou ainda que, embora seja verdade que o governo NPP teve que lidar com os preços do petróleo que aumentaram progressivamente durante seu mandato, a crise econômica gradual que atingiu o pico em 2009 não levou o governo a reexaminar suas políticas econômicas e nem criar novas fontes de câmbio extrangeiro para compensar os problemas econômicos emergentes. O governo do NPP estava, da mesma forma, preso no surto de gastos baseado em eleições. Enquanto o governo NPP poderia evitar gastos relacionados às eleições em 2004 porque estava suficientemente certo da vitória, "a eleição de 2008 demonstrou que um governo NPP estava disposto a usar seu poder de compra para ganhos eleitorais quando não tinha certeza da decisão dos eleitores” (Killick 2010, p. 415). O impacto de tais gastos imprudentes politicamente motivados na economia de Gana foi significativo ${ }^{8}$. Assim, quando o governo NPP deixou o cargo em 2009, a economia não melhorou muito, continuando tão falida quanto quando eles assumiram o controle em 2001 (Lindsay 2011b, p. 25).

Apesar das dificuldades econômicas, no entanto, parece que a trégua obtida anteriormente com a iniciativa HIPC, permitiu que o governo NPP se comprometesse com um nível considerável de gastos sociais, incluindo aumentos nos salários dos trabalhadores. Os salários dos trabalhadores melhoraram substancialmente - de fato, em 2002, tanto o menor quanto o maior salário real dos trabalhadores aumentaram para $11,6 \%$ e 12,9\%, respectivamente. Da mesma forma, em 2003, os salários reais mais baixos e mais altos aumentaram em 22,5\% e 34,9\%. Em 2005, os salários reais aumentaram em mais de 28\% (Bank of Ghana 2007, p. 8; Amoako-Gyampah 2015, p. 67). Entretanto, esses aumentos nos salários durante o governo de NPP, assim como na gestão anterior do NDC, também tiveram de enfrentar os protestos trabalhistas, especialmente depois de 2004. Os trabalhadores protestavam e embarcavam em greves esporádicas para exigir mais melhorias nos salários e melhores condições de trabalho. Em outros lugares, argumentei que mesmo os chamados ganhos macroeconômicos que o governo NPP foi capaz de alcançar pareciam superficiais e não refletiam, na prática, sobre as condições de vida e trabalho dos trabalhadores (ver AmoakoGyampah, 2015).

A decisão do governo, após 2004, de descontinuar o pagamento dos subsídios aos produtos petrolíferos e o repasse subsequente das mudanças no preço do cídi dos custos internacionais do petróleo e produtos petrolíferos para os 
consumidores do Gana, juntamente com aumentos astronômicos nas tarifas dos serviços públicos (Gocking 2005; Amoako 2015), parece ter prejudicado a trégua obtida pelos ajustes de alta nos salários dos trabalhadores. Como era de se esperar, tais desenvolvimentos não foram recebidos com tranquilidade pela população trabalhadora, uma vez que a frente de trabalho viu várias greves e paralisações sem aviso prévio (ver Amoako-Gyampah 2015). Gocking (2005) sugeriu que os trabalhadores dificilmente se beneficiariam dos supostos êxitos econômicos da administração do NPP aclamados pelas agências doadoras. Consequentemente, após 2004, o governo estava sob pressão para lidar com os excessos orçamentários irresponsáveis decorrentes da enorme massa salarial do setor público (Centre for Economic Policy Analysis, 2009; Amoako-Gyampah 2015). O governo, portanto, não estava disposto a ceder prontamente às demandas dos trabalhadores pelo aumento de seus salários nos anos anteriores a 2004, o que resultou em uma forte agitação trabalhista (ver Amoako-Gyampah 2015). O governo foi forçado a ceder às exigências dos trabalhadores, uma vez que quaisquer aumentos salariais substanciais poderiam ter agravado as tendências inflacionárias da economia do Gana - tendências que permeiam a história econômica de Gana desde os anos 1960, embora com impactos variados.

Penso que, enquanto a abertura do espaço democrático com a inauguração da Quarta República parecia ter permitido que a mão de obra organizada operasse livremente, as restrições econômicas e as políticas fiscais do governo frustraram seus esforços para alcançar aumentos salariais substanciais, além de melhorias nas condições de serviço dos trabalhadores ganenses. Por essa razão, tem havido uma relação adversária entre o trabalho organizado e o governo desde 1992. Haynes (1995) observou que muitos dos trabalhadores sindicalizados e politicamente conscientes em Gana, acreditavam que o governo negou voluntariamente aos trabalhadores aumentos consideráveis no valor real do salário mínimo. Se esse sentimento dos trabalhadores fosse verdadeiro para com a administração do NDC, o mesmo poderia ser dito durante o mandato da administração do NPP. Podemos supor então que, sob as considerações econômicas da Quarta República de Gana, mais do que qualquer outra coisa parecia ter sido fundamental para as ações populares de descontentamento e protesto. As agitações dos professores e os atos de protesto sob a Quarta República foram influenciadas e condicionadas pela economia política mais ampla que, assim como outros trabalhadores do setor público, reagiram aos altos e baixos das políticas macroeconômicas e fiscais dos 
governos que impactaram negativamente em suas políticas, condições de trabalho e de vida. Nas seções seguintes, discuto as queixas dos professores e os protestos desde $1993^{\circ}$.

\section{GREVES DOS PROFESSORS NO CONTEXT DA NDC (1993-2000)}

Os professores organizados estavam entre o primeiro grupo de trabalhadores a levantar a bandeira vermelha nos primeiros anos da década de 1990, quando o ambiente político estava relaxado e acomodado quanto às ações de protesto ${ }^{10}$. A GNAT declarou uma greve nacional em março de 1990. A greve durou duas semanas e pedia melhorias nos salários e subsídios básicos; estabelecimento de um comitê de negociação conjunto para a determinação regular de salários e benefícios associados; o estabelecimento do Ghana Education Service Council (Conselho de Serviços Educacionais do Gana), que o regime do PNDC havia abolido em 1982; e a plena implementação de todas as condições de serviço existentes (Ampaw 1995, p. 29; Amoako 2014c, p. 18). O governo prometeu resolver as queixas e pediu aos professores que retornassem ao trabalho, uma vez que buscaria uma solução eficaz (Amoako 2014c). Após o fracasso do regime do PNDC e do governo sucessor do CND em resolver as demandas dos professores, a GNAT declarou, mais uma vez, uma greve em 31 de maio de 1994, pressionando o governo a lidar com as queixas de longa data. Para além da exigência de pagamento de bonificações ex-gratia para "professores-alunos" demitidos que trabalharam para o Serviço Educacional do Gana durante um período de cinco anos (ver Amoako, 2014c), todas as outras exigências na greve de 1994 relacionavam-se com o fato de os professores terem levantado, desde a década de 1980, que o regime do PNDC não conseguiu atender às reinvidicações (Ampaw, 1995, pp. 29-30). Além dessa greve, a GNAT declarou litígio mais uma vez e convocou uma greve de seis dias em 1999, que viu cerca de 50.000 professores saindo da sala de aula para exigir aumentos salariais e pagamentos atrasados. Em 2000, A NAGRAT também declarou uma ação grevista que envolveu 5.000 professores pedindo ao governo para colocar professores de com formação acadêmica em um nível de entrada separado na escala do Gana Education Service, para corresponder ao nível 15 da Estrutura Salarial Universal de

9 N.A.: As seções a seguir trazem dados de publicações anteriores do autor sobre este assunto (ver Amoako 2014b; Amoako-Gyampah 2015).

10 N.A.: $\mathrm{O}$ governo PNDC foi menos tolerante às manifestações durante a década de 80. Foram utilizadas medidas de repressão para banir quaisquer formas de protesto. Apesar disso, no início dos anos 90 , quando ficou óbvio que a transição democrática era inevitável, o regime atenuou as medidas repressivas como uma maneira de atrair o apoio popular - uma vez que ele se reinventou, transformando o PNDC em NDC - um jogo eleitoral para concorrer nas eleições de 1992. 
Gana (GUSS) (Amoako 2014c, p. 23). Implicitamente, os professores licenciados exigiam salários mais altos, já que a colocação naquele nível no GUSS significava um aumento automático de seus salários. O governo resolveu esta greve e colocou os professores profissionais graduados no nível 14 do GUSS.

Dois pontos de análise podem ser avançados para explicar por que as ações de greve se tornaram uma ferramenta importante para os professores organizados nos primeiros anos da década de 1990. Em primeiro lugar, pode-se dizer que foi a intransigência dos governos do PNDC/NDC, que muitas vezes recorreram a táticas burocráticas demoradas para resolver as reinvidicações dos professores que muitas vezes obrigaram a GNAT a convocar seus membros para recorrer a ações grevistas (Amoako, 2014b). Os eventos que levaram à greve de 1994, por exemplo, são reveladores. Em abril de 1993, a GNAT fez um acordo para se encontrar com o Ministro da Educação, Harry Sawyer, para apresentar a ele suas reivindicações. A GNAT acompanhou esta reunião com um memorando sobre questões educacionais, apresentado ao Ministro em 17 de maio de 1993 (GNAT 1993; Amoako, 2014c). Este memorando foi seguido de várias outras cartas indicando as queixas dos professores e solicitando soluções do governo (Amoako 2014c).

O governo não respondeu verbalmente ou por escrito a qualquer uma dessas cartas e memorando (Osei-Mensah, 1994). Apesar deste fracasso por parte do governo, a GNAT continuou a procurar meios não conflituosos para resolver suas reivindicações, buscando oportunidades de realizar reuniões com o Ministro da Educação para apresentar a ele suas preocupações. Por exemplo, entre 10 de fevereiro e 31 de maio de 1994, a GNAT realizou quatro reuniões com o Ministro da Educação para discutir suas exigências. No entanto, nenhuma dessas reuniões produziu qualquer resultado positivo, com exceção de que, em uma dessas reuniões, o Ministro prometeu apresentar as exigências da GNAT ao Gabinete para análise (GNAT 1994). Em outra reunião convocada em 25 de abril, por ocasião do Ministro, após a ameaça da GNAT de iniciar uma greve (Amoako 2014c, p. 21), o Ministro prometeu atender todas as reivindicações da GNAT. Posteriormente, ele esclareceu como ele estava procedendo para atender às queixas dos professores (Amoako 2014, p. 21). No entanto, quando em 31 de maio de 1994, a GNAT se reuniu com o ministro para esclarecimentos, ficou claro para a liderança da GNAT que o ministro havia adotado um labirinto burocrático, frustrando assim suas tentativas de atender às exigências - pois o ministro havia feito pouco ou nada concreto para assegurar à GNAT seu compromisso em contornar a situação (Osei-Mensah 1994, p. 13). Foi por causa disso que a GNAT convocou seus membros para iniciar uma greve em 31 de maio de 1994 (ver Seini 1994, p. 9). Fica claro, portanto, que embora a GNAT tenha 
permanecido extremamente conciliatório para resolver suas queixas, o governo e seus funcionários estavam bastante atrasados e pareciam agir de má-fé. Assim, parece que se o governo tivesse sido um pouco proativo na solução das queixas dos professores, essas greves poderiam ter sido evitadas.

Em segundo lugar, parece que as reivindicações dos professores, assim como as de outros trabalhadores do setor público, foram motivadas por suas condições econômicas em constante deterioração, o que os levaram a exigir salários mais altos e melhores condições trabalhistas para diminuir sua precariedade. De fato, apesar das tentativas modestas de transformar a economia de Gana desde os anos 80, as políticas de liberalização adotadas pelo governo PNDC após a implementação dos programas de recuperação e ajuste econômico prejudicaram muito a população trabalhadora. A necessidade de limitar os aumentos salariais em consonância com as políticas de ajustamento (ver Nugent, 1995, p. 169) levara a uma situação em que, até 1995 , os salários reais dos trabalhadores do setor público haviam caído até a metade do que era $1970^{11}$ (ver Overa 2007, p. 541). Como Hansen (2003) observou adequadamente, as políticas de ajuste, apesar de sua glorificação pelos doadores ocidentais e suas instituições afins, levaram os trabalhadores ganenses do setor formal a enfrentar as dificuldades econômicas. A remoção dos subsídios dos produtos petrolíferos e as tarifas de eletrificação, mesmo enquanto o governo permaneceu restrito para amortecer os trabalhadores do setor público com aumentos salariais (como medidas para estabilizar a economia), empobreceram a população trabalhadora.

Foi o resultado da difícil situação econômica em que os trabalhadores comuns ganenses se encontravam que, entre 1991 e 1995, o Consultative Forum of Labour (Fórum Consultivo do Trabalho) que incluía a GNAT, a Associação dos Servidores Públicos (CCSA), a Associação Gana de Enfermeiros Registados (GRNA) e a Associação de Serviços Judiciais (JUSAC) estava engajado em uma difícil luta com o governo por salários mais altos e melhores condições trabalhistas. A relutância do governo em aceitar as demandas do Fórum e dar aos trabalhadores qualquer aumento de renda relevante, resultaria em ações esporádicas de greve, onde enfermeiros foram às ruas em maio/junho de 1992, seguido por outros funcionários públicos durante as duas primeiras semanas de julho do mesmo ano (Ampaw 1995, p. 29-30). Após o anúncio do austero orçamento do ano fiscal de 1993, o Fórum exigiu um aumento de $60 \%$ em sua receita, a fim de recuperar a perda orçamentária causada pelos aumentos de preços e pelas pressões inflacionárias associadas - ao que o regime era relutava em aderir

11 N.A.: Os professores estavam na mesma faixa salarial de outros funcionários do setor público. 
(Ampaw 1995, p. 29). O resultado foi: manifestações massivas e ameaças de ações grevistas ao longo de 1993, com repercussões nos anos seguintes. Como Kumado e Gockel (2006) observaram:

A insuficiência da receita foi agravada por altíssimas taxas de inflação e pela depreciação da taxa de câmbio, de modo que aqueles com renda fixa, especialmente aposentados, ficaram em piores condições. Por exemplo, embora a inflação tenha baixado de seu nível mais alto de 123\% em 1983 para 10\% até o final de 1992, permaneceu turbulenta. De fato, a inflação, juntamente com o declínio constante da taxa do cídi / dólar, que reflene na economia, tem sido, desde então, a ruína dos trabalhadores (p. 3).

Assim, pode-se supor que a causa raiz desse impasse governo-trabalho, do qual a mobilização da GNAT fazia parte, era a questão dos salários e vencimentos - essencialmente, uma luta para melhorar os benefícios materiais dos professores. Portanto, parece partir da análise anterior que os efeitos das restrições macroeconômicas do Gana alimentaram parte das agitações dos professores e que o atraso do governo em resolver essas queixas resultou nas ações de greves esporádicas, que se tornaram uma característica no cenário do trabalho educacional durante o período.

\section{O REGIME NPP: NOVAS PERSPECTIVAS PARA PROFESSORES?}

Depois de dois mandatos sucessivos de governo do NDC sob a liderança de Rawlings, o novo candidato presidencial do NDC, professor John Evans Atta-Mills, perdeu as eleições presidenciais no segundo turno em dezembro de 2000, para John Agyekum Kufour, do NPP. Como mencionei anteriormente, o governo NPP herdou uma economia turbulenta. No entanto, talvez devido à capacidade do novo governo de articular claramente a posição econômica do país e as medidas propostas para reverter a economia, recebeu boas vibrações dos ganenses em geral e da população trabalhadora em particular. Seus esforços na implementação e promulgação de uma nova lei trabalhista, a Lei do Trabalho 651, que estava em curso desde os anos 90 , foi recebida pela organização trabalhista como um marco na história laboral de Gana. Posteriormente, o primeiro mandato da gestão do governo NPP testemunhou menos disputas trabalhistas. Isso não quer dizer, no entanto, que não houveram tensões na frente de trabalho. Os professores, em particular, liderados pela GNAT, ameaçaram embarcar em uma greve em $1^{\circ}$ de outubro de 2001 para exigir melhores condições de serviço e a 
implementação do subsídio de supervisão ${ }^{12}$. Da mesma forma, a NAGRAT ameaçou parar seus serviços a partir de 28 de abril de 2004 na demanda por maior subsídio de supervisão. Em ambos os casos, as ameaças foram retiradas porque, de acordo com os professores, a posição do governo sobre suas queixas parecia coerente e aceitável (Amoako 2012, p. 95; Amoako 2015).

Essas relações industriais aparentemente harmoniosas no setor educacional permaneceram apenas até o final de 2004 pois, em 2005 e $2006^{13}$, o setor de educação testemunhou algumas das disputas trabalhistas mais prolongadas na história do trabalho de Gana. Curiosamente, NAGRAT estava na frente dessas agitações. Isso não quer dizer que as questões sobre as quais a NAGRAT declarou as ações de greve referiam-se apenas aos professores graduados. As questões afetavam também os professores sem titulação e, de fato, em 2006, os membros da GNAT declararam greves esporádicas em solidariedade à NAGRAT, ainda que a liderança da GNAT tenha se distanciado da greve (ver Amoako-Gyampah 2015) ${ }^{14}$. Em 6 de maio de 2005, a NAGRAT declarou uma ação grevista em protesto contra a atitude indiferente do governo em resolver suas reivindicações, incluindo: falha dos Serviços Educacionais do Gana (GES) em atender às demandas dos professores por aumento do subsídio de supervisão; a relutância do Ministério da Educação e do GES em aprovar e definir datas para a promoção de diretores assistentes e níveis superiores a este; o atraso do GES na emissão de cartas para professores que foram promovidos aos cargos de Superintendentes e Diretores Superintendentes; o fracasso do GES e do Conselho de Exames da África Ocidental (WAEC) em pagar os subsídios totais de supervisão devidos aos professores (Gobah 2005, p. 3; Amoako 2015, p.11).

As reivindicações para a maioria dessas demandas começaram desde janeiro de 2004. A NAGRAT escreveu várias cartas, apresentou vários

12

N.A.: Subsídios de supervisão e monitoramento são pagos aos professors que têm responsabilidades adicionais como supervisores e monitores em avaliações externas no Serviço Educacional do Gana. O Serviço Educacional do Gana depende do Conselho de Exame da África Ocidental (WAEC) para organizar o Basic School Certificate Examination (Exame de Certificação da Educação Básica), exame para entrar no ensino médio. Um exame similar - o West African Senior High School Certificate Examination (Exame de Certificação de Ensino Médio da África Ocidental) é uma prova de qualificação para entrar em instituições universitárias que é conduzido pela mesma organização.

13

N.A.: Para uma análise detalhada sobre essas manifestações, ver Amoako (2015)

14 N.A.: Parece que depois de vários anos operando nos bastidores do campo de trabalho educacional desde seu registro e inauguração em 2008, a NAGRAT estava neste momento afirmando sua presença na área de trabalho de educação. É claro que a formação da NAGRAT foi estimulada pelas percepções de que a GNAT estava relutante em buscar o interesse de seus associados com licenciatura. Além disso, parecia menos provável que, com duas mulheres ocupando as posições de liderança mais importantes da GNAT, poder-se-ia esperar uma agitação intensa da GNAT. Em 2002, Irene Duncan Adanusa, a primeira secretária geral da GNAT do sexo feminino, substituiu Paul Osei Mensah, que servia desde 1983. A posição presidencial também coube a Portia Molly Anafo. Com seus instintos maternais e preocupação com as crianças, só se podia esperar uma agitação cautelosa por parte da GNAT. 
memorandos e realizou várias reuniões com o Ministério da Educação - tudo isso na tentativa de resolver essas questões. Em alguns casos, houve ameaças e contra ameaças tanto do Ministério da Educação como do GES, por um lado, e da NAGRAT, por outro. No entanto, nenhuma conclusão concreta foi alcançada, e a frustração resultante estimulou a NAGRAT a recorrer à greve como última opção (Amoako 2015, pp 11-13). Cerca de um mês depois da greve, o Education Subcommittee of Ghana's Parliament (Subcomitê de Educação do Parlamento de Gana) ofereceu-se para intermediar a paz entre a NAGRAT e o governo. O Comitê conseguiu persuadir NAGRAT a retornar ao trabalho, enquanto continuava com as negociações para encontrar uma solução definitiva para a disputa. Parece que, uma vez que os professores retomaram o trabalho, pouco foi feito para atender suas queixas (ver Amoako 2015). O fracasso do GES e do Ministério da Educação em encontrar uma solução definitiva para as demandas dos professores reforçou, assim, o recurso à greve da NAGRAT em 2006.

A greve da NAGRAT de 2006 começou em 1 de setembro de 2006 e continuou por quase oito semanas. Além da exigência para governo para implementar todas as reivindicações pendentes extraídas do Memorandum of Understanding (Memorando de Entendimento), incluindo subsídios de supervisão, pagamento de subsídios de responsabilidade ${ }^{15}$, emissão de cartas de conversão para todos os professores graduados, independentemente de serem profissionais ou não; A NAGRAT também exigiu estar representado em todos os comitês e painéis do GES e também no Conselho do GES - que é o corpo diretivo do setor de educação, e exigiu o reembolso dos professores cujos salários não estavam sendo pagos desde 2003 (Amoako-Gyampah 2015). A maioria dessas demandas eram queixas não resolvidas da greve de 2005 , e que haviam sido reafirmadas. A preocupação central durante a greve de 2006, no entanto, foi a demanda pelo aumento salarial. Assim como os eventos que levaram à greve de 2005, a NAGRAT havia esvaziado os canais formais e informais para resolver suas queixas antes de finalmente decidir entrar em greve. Após uma ameaça em março de 2006 para iniciar uma greve se suas queixas de 2005 não fossem resolvidas, o Ministro da Educação, Yaw Osafo Marfo, interveio e persuadiu os professores a retirar sua ameaça, prometendo assegurar que as exigências dos professores fossem resolvidas (NAGRAT 2006; Amoako-Gyampah 2015). Curiosamente, o ministro foi removido do cargo antes que pudesse ver a execução de sua promessa e nem seu sucessor nem o GES e o Ministério da Educação tomaram medidas concretas para tratar das preocupações dos professores. Foi esse fracasso da parte das autoridades educacionais que incitou a NAGRAT a convocar a greve. 
É óbvio, pela narrativa acima, que tanto nas ações grevistas de 2005 quanto em 2006, foi a má vontade do governo de encontrar soluções duradouras para as queixas dos professores que incitaram NAGRAT a embarcar em ações grevistas. Em ambos os casos, os professores usaram vários canais de negociação para buscar respostas e recorreram a ações de greve apenas como último recurso (ver Amoako-Gyampah 2015). Suas exigências se referiam fundamentalmente a demandas por melhorias em suas condições trabalhistas e manifestações para aumentos salariais. Devo, no entanto, observar que, com relação aos salários, o governo do NPP aumentou consideravelmente os salários dos professores. Por exemplo, em 2003, o salário mensal de um professor não licenciado era, em média, de $\notin 1.422 .836,00$ (equivalente a US $\$ 160,7)^{16}$. Durante o mesmo período, professores licenciados receberam um salário mensal $\$ 1.641 .465,00$ (equivalente a US\$185,4) em média. Em 2006, a média salarial mensal do professor não licenciado aumentou para $\$ 2.400,105$ (equivalente a US\$270,4) e o do profissional licenciado para $₫ 2.877 .726,00$ (equivalente a US\$313,5) (Amoako-Gyampah 2015, p. 68). Assim, em um espaço de três anos, os salários de professores licenciados e não licenciados praticamente dobraram.

No entanto, a demanda por aumentos salariais e melhoria nas condições relacionadas ao serviço tornou-se fundamental para as agitações dos professores tanto em 2005 quanto em 2006. Como afirmei anteriormente, a desregulamentação do mercado petrolífero e o consequente encargo para os consumidores do Gana de pagar preços reais de mercado pelos produtos petrolíferos, bem como um aumento nas tarifas dos serviços públicos, além outras medidas de redução de custos adotadas pelo governo NPP para estabilizar a macroeconomia, parece ter minado os aumentos salariais que o governo ofereceu aos trabalhadores ganenses. Além disso, o governo estava sob pressão para encontrar maneiras de minimizar a dívida salarial do setor público, que se tornara a ruína dos gastos do governo, além de um dos principais fatores que contribuíram para os excessos orçamentários. Foi por essa última razão que o governo adotou uma decisão tática para adiar a negociação salarial e os acordos salariais durante o ano fiscal de 2005 (ver Center for Economic Policy Analysis 2009) - uma medida que salvou o país de um valor equivalente a $0,4 \%$ do PIB. Curiosamente, tal decisão contribuiu em parte para a

16 N.A.: Uma carga horária máxima de 8 h por dia ou $40 \mathrm{~h}$ semanais é estabelecida para todos os trabalhadores do setor público, inclusive professores. No entanto, professores da educação básica mantém contato com os alunos durante 7 horas por dia. Existe um contrato comum para todos os professores de escolas públicas do Gana e suas variações vão de acordo com o nível de qualificação e duração do serviço. Isso quer dizer que os professores são promovidos e classificados de acordo com sua qualificação e tempo de serviço. Portanto, a média salarial é mensurada pela categoria. Por exemplo, professores qualificados recém-admitidos começam como Superintendente Sênior II, os licenciados são contratados como Superintendentes Superiores, seguidos pela promoção aos cargos de Diretor Assistente, Diretor Adjunto e Diretor depende de um longo tempo de serviço e de ter passado por uma entrevista de promoção. 
manifestação trabalhista que foi testemunhada em 2005 e 2006, respectivamente (ver Amoako-Gyampah 2015). De fato, um pesquisador declarou 2006 como a temporada de greves devido ao número de disputas trabalhistas que foram registradas - tudo por causa dos salários e das melhorias nas condições trabalhistas (Coleman 2006; Amoako-Gyampah 2015).

\section{CONCLUSÃO}

As mobilizações dos professores, no âmbito da Quarta República de Gana, manifestaram-se sob a forma de greves para exigir aumentos salariais e melhorias nas condições de trabalho dos professores. No entanto, as organizações de professores recorreram às greves apenas como último recurso para atender às suas reivindicações, às quais os sindicatos dos professores têm procurado atender através dos canais de negociação disponíveis. Ainda assim, os vários governos que geriram o Gana desde a inauguração da Quarta República, primeiro o NDC e depois o NPP, frustraram os esforços dos sindicatos e permaneceram atrasados (negociando de má fé) nas soluções das queixas dos professores. Parece, portanto, que é a atitude indiferente dos governos em atender as reivindicações dos professores, que muitas vezes levaram os sindicatos dos professores a declarar ações grevistas. No entanto, estes movimentos grevistas foram alimentados pelos altos e baixos da economia política incerta de Gana, e pelas medidas macroeconômicas do governo e o seu impacto negativo nas condições de vida e de trabalho da categoria docente. Parece também que a negligência do governo em responder pontualmente às reclamações dos professores foi moldada e condicionada, em parte, pelo seu compromisso de implementar suas medidas econômicas, a maioria das quais tem sido impopular entre a população trabalhadora. As restrições econômicas definiram assim as manifestações dos professores, bem como a falta de respostas do governo.

\section{REFERÊNCIAS}

Adu-Amankwa, K. \& Tutu, K. (1997). 'Ghana: Going beyond Politics.' In Trade Unions and Sustainable Democracy in Africa, Kester, Gerard \& Sidibe, Oumarou Ousamne (Ed). 207-228. England \& USA: Ashgate Publishing Company.

Amoako, S. (2012). 'Teachers' Unions and Politics in Ghana and South Africa, 1990-2010. 'Unpublished Master's Dissertation, University of Johannesburg, South Africa. 
Amoako, S. (2014a). 'Teaching and Labour: Teacher Unionism in Ghana, 19311966.' International Journal of African Historical Studies, vol. 47 no 1, pp $55-75$.

Amoako, S. (2014b). 'The Ghana National Association of Teachers Under the Provisional National Defence Council, 1982-1991: Caught in a Warp of Cooperation and Unresolved Grievances.' Contemporary Journal of African Studies, vol. 2 no. 1, pp. 1-25.

Amoako, S. (2014c). 'Black Board Struggles: Teacher Unionism under the 'Democratic' Rawlings Regime, 1992-2000.' Ghana Studies, Vol. 17. pp. 7-38.

Amoako-Gyampah, A. K. (2015). "Striking Where It Hurts: The Political Economy of Graduate Teachers Strikes and Labour Relations in Ghana's Public Education Sector African Review of Economics and Finance, Vol. 7, no. 2. pp. $60-83$

Ampaw, A. (1995). 'The state of the Nation: Rumblings on the Labour Front.' In Ghana: The Kumepreko Demonstrations, Poverty, Corruption and the Rawlings Dictatorship, Napoleon Abdulai (Ed.). pp 21-33. London: Africa Research and Information Bureau.

Aryeetey, E. \& Kanbur, R. (2008). 'Ghana's Economy at Half-century: An Overview of Stability, Growth and Poverty.' In The Economy of Ghana: Analytical Perspectives on Stability, Growth and Poverty, Ernest Aryeetey \& Ravi Kanbur (Ed). Pp. 1-19. Oxford: James Curry Ltd.

Asiedu-Akrofi, K. (1971). Teachers' Association in Ghana: An Analytical Study. Cape Coast: University Press.

Ato-Coleman, H. 2006. "A Season of Strikes in Ghana: A Rapid Analysis.” Daily Graphic, 21 June.

Bob-Milliar, G, and Bob-Milliar K. G. (2010). 'The Economy and Intra-Party Competition: Presidential Primaries in the New Patriotic Party of Ghana.' African Review of Economics and Finance vol. 1, no 2 pp. 51-71.

Compton, M. \& Weiner, L. (2008). The Global Assault on Teaching, Teachers and their Unions: Stories of Resistance. New York: Palgrave Macmillan. 
Darkwah, K. (2014). A History of GNAT. Accra: Woeli Publishers

GNAT (1993). 'Memorandum on Educational Issues submitted to the Ministry of Education.' Accra: GNAT Archives.

Gocking, S. R. 2005. The History of Ghana. Greenwood Press.

Hansen, T. K. (2003). 'Creative Allocation of Space as a response to Economic Crises.' In Critical Perspectives in Politics and Socio-economic Development in Ghana, Wisdom Tettey J, Puplampu, Korbla, \& Bruce, J. Berman (Ed). Pp. 93-115. Leiden \& Boston: Brill.

Haynes, J. (1995). 'Ghana: From Personalist to Democratic Rule.' In Democracy and Political Change in Sub-Saharan Africa, John A. Wiseman (Ed). Pp. 9315. London \& New York: Routledge.

Herbst, J. (1991). "Labour in Ghana under Structural Adjustment: The Politics of Acquiescence" in Ghana: The Political Economy of Recovery, Rothchild, Donald (Ed). Boulder and London: Lynne Rienner Publishers

Hutchful, E. (2002). Ghana's Adjustment Experience: The Paradox of Reform. Geneva: UNRISD.

Jefferies, R. (1978). Class, Power and Ideology in Ghana: The Railwaymen in Sekondi. Cambridge: Cambridge University Press.

Jefferies, R. (1982). "Rawlings and the Political Economy of Underdevelopment in Ghana." African Affairs, Vol. 81, no. 324. Pp. 307-317

Jeon, H. (1996). 'Ghana: Lurching Toward Economic Rationality.' World Affairs, vol. 159, no. 2. Pp. 64-71

Jeon, H. (1998). 'Economic Reform and Democratic Transition in Ghana.' World Affairs, vol. 160, no. 4. Pp. 218-230.

Killick, T. (2010). Development Economics in Action: A Study of Economic Policies in Ghana (2nd edition). USA \& Canada: Routledge. 
Kraus, J. (2007). 'Trade Unions, Democratization, and Economic Crises in Ghana.' In Trade Unions and the Coming of Democracy in Africa, Jon Kraus (Ed). Pp. 83-121. New York: Palgrave Macmillan.

Kraus, J. (1979). 'Strikes and Labour Power in Ghana'. Development and Change, Vol. 10. pp. 259-86

Kumado, K. \& Gockel, A. F. (2006). 'A study on Social Security in Ghana.' Unpublished Manuscript.

NAGRAT, (2006). "Intended Industrial Action on Hold". Press Release, Ref No. NGT/NS/P-S/009/06. NAGRAT Archives, Accra.

Nugent, P. (1995). Big Men, Small Boys and Politics in Ghana: Power, Ideology and the Burden of History. Ghana: Asempa Publishers.

Osei, M. G. (2006). 'Teachers in Ghana: Issues of Training, Remuneration and Effectiveness.' International Journal of Educational Development, vol. 26. No 1. Pp 38-51

Osei-Mensah, P. (1994). ‘The Teachers’ Cause.' Daily Graphic July 20. Pp. 3 \&13.

Overa, R. (2007). 'When Men do Women's Work: Structural Adjustment, Unemployment and Changing Gender Relations in the Formal Economy of Accra, Ghana.' Journal of Modern African Studies, vol.45, no. 4. Pp. 539-563.

Republic of Ghana (2001). State of the Nation Address. Accra: Assembly Press.

Robertson, S (2000). A Class Act: Changing Teachers Work, the State and Globalisation. New York: Falmer Presss

Sang, A. K. (2002). 'Interest Groups in Education: Teachers' Perceptions of the Effectiveness of the Kenya National Union of 'Teachers.' Unpublished PhD Dissertation, University of Cape Town.

Seini, I. (1994). 'Teachers to go on strike on May 31.' Daily Graphic, May 27. 
Whitfield, L. (2011a). 'Competitive Clientelism, Easy Financing and Weak Capitalists: The Contemporary Political Settlement in Ghana.' Danish Institute for International Studies Working paper, no. 27

Whitfield, L. (2011b). 'Growth without Economic Transformation: Economic Impacts of Ghana's Political Settlement.' Danish Institute for International Studies Working paper, no. 28.

AKWASI KWARTENG AMOAKO-GYAMPAH [anteriormente conhecido e chamado Samuel Amoako] é doutorando no Departamento de Estudos Históricos da Universidade de Joanesburgo, África do Sul. Antes de se inscrever para o doutorado, lecionou no Departamento de História da Educação, Universidade de Educação, Winneba, Ghana, onde tirou licença para estudos em 2016. Suas publicações apareceram no International Journal of African Historical Studies (2014), Ghana Studies (2014), Journal of Asian and African Studies (2014), Contemporary Journal of African Studies (2014), e African Review of Economics and Finance (2015). Seus interesses pelos estudos africanos abrangem a economia política, história comparada da escravidão, história econômica, e história social da medicina e saúde pública. Sua pesquisa atual enfoca o saneamento e a higiene pública na Gana colonial e pós-colonial. E-mail: akwasikwarteng_amoakogyampah@yahoo.com 